\title{
KARAKTERISTIK KESTABILAN LERENG DAERAH JATIGEDE, KABUPATEN SUMEDANG, PROVINSI JAWA BARAT BERDASARKAN ANALISIS KINEMATIK
}

\author{
Characteristics of Slope Stability at Jatigede Area, Sumedang \\ Regency, West Java Province Based on Kinematic Analysis
}

\author{
SOFYAN RACHMAN', DICKY MUSLIM², NANA SULAKSANA² dan M. BURHANNUDINNUR ${ }^{1}$ \\ ${ }^{1}$ Prodi Teknik Geologi - Universitas Trisakti \\ Jalan Kyai Tapa 1, Grogol, Jakarta Barat 14430 \\ e-mail: sofyan@trisakti.ac.id \\ ${ }^{2}$ Fakultas Teknik Geologi - Universitas Padjadjaran \\ Jalan Raya Bandung Sumedang Km 21, Jatinangor 45363
}

\begin{abstract}
ABSTRAK
Daerah penelitian secara administratif berada di Kecamatan Jatigede, Kabupaten Sumedang, Provinsi Jawa Barat. Berdasarkan sudut pandang geologi, daerah Jatigede memiliki beberapa permasalahan yang timbul akibat kondisi geologi daerah tersebut yaitu berupa pengaruh keberadaan struktur geologi yang berhubungan dengan stabilitas maupun keruntuhan lereng. Untuk dapat mengidentifikasi tipe keruntuhan lereng batuan, dapat dilakukan analisis kinematik menggunakan metode scanline sampling. Penelitian ini dibagi menjadi 15 lokasi scanline sampling. Pada penelitian, dilakukan juga perhitungan uniaxial compressive strenght (UCS) dan rock quality designation (RQD) pada lereng tumpuan barat Bendungan Jatigede. Hasil analisis kinematik mendapatkan potensi tipe keruntuhan baji pada lereng scanline (SL) 1, 4 - 11 sedangkan pada lereng SL 2 dan 3 tidak memenuhi syarat keruntuhan baji serta didapatkan kualitas massa batuan (RQD) sedang-sangat baik serta penentuan nilai UCS yang menunjukan kekuatan material batuan yang lemah.
\end{abstract}

Kata kunci : Bendungan Jatigede, uniaxial compressive strenght, keruntuhan lereng, analisis kinematik

\begin{abstract}
The research area is administratively located in Jatigede Sub-District Sumedang Regency, West Java. Based on geology perspective, Jatigede has some problems that are arisen due to its geological conditions, namely the presence of a geological structure, including the failure of a slope. To identify the type of slope failure, it can be conducted kinematic analysis logging using a scanline sampling method. The research is divided into 15 locations of scanline sampling. The study also performed calculations of uniaxial compressive strenght (UCS) and rock quality designation (RQD) of the slopes at the West bank of Jatigede Dam. Results of kinematic analysis for potential failure of wedge occurs at the slopes of the scanline (SL) 1, 4-11 while on the slopes of the scanline (SL) 2 and 3 does not qualify the wedge failure. Based on the calculation of the RQD of rock mass quality is obtained,fair-very good as well as the determination of UCS values showed the strength of the weak rock material.
\end{abstract}

Keyword : Jatigede Dam, Uniaxial Compressive Strenght, slope failure, kinematic analysis 


\section{PENDAHULUAN}

Berdasarkan laporan yang disusun oleh Warman dan Indrawan (2015), kondisi geologi teknik Bendungan Jatigede menunjukkan pergerakan lereng yang sangat dekat dengan tubuh bendungan sehingga dikhawatirkan akan memengaruhi kestabilan tubuh bendungan secara keseluruhan.

Penelitian ini dilakukan untuk mengevaluasi kestabilan lereng batuan tumpuan barat Bendungan Jatigede melalui klasifikasi massa batuan dan perhitungan slope mass rating (SMR) (Romana, 1985 dalam Zakaria $d k k$., 2013). Berdasarkan pemetaan geologi dan geologi teknik permukaan diharapkan dapat memberikan kontribusi dalam upaya peningkatan kestabilan lereng batuan pada tumpuan barat Bendungan Jatigede.

Tujuan penelitian ini adalah untuk menentukan kondisi geologi dan geologi teknik daerah penelitian melalui pemetaan geologi dan geologi teknik serta menganalisis kestabilan lereng batuan pada tumpuan barat Bendungan Jatigede melalui scanline sampling, klasifikasi massa batuan dan perhitungan SMR (Romana, 1985 dalam Prasetya $d k k$., 2015), serta memberikan rekomendasi menggunakan perhitungan empiris mengenai penanganan terhadap stabilitas lereng.

\section{Geologi Umum}

Menurut Bemmelen (1949) secara fisiografi, daerah penelitian termasuk ke dalam Zona Bogor bagian timur. Zona ini merupakan antiklinorium yang cembung ke utara dengan arah sumbu lipatan barat-timur. Djuri (1973) menyebutkan stratigrafi daerah penelitian mulai dari batuan tertua sampai termuda pada daerah penelitian adalah sebagai berikut:

1. Formasi Halang yang terdiri dari anggota Halang Bawah berupa breksi gunungapi bersifat andesitik sampai basaltik, batulempung, tufa dan konglomerat. Anggota Halang Atas terdiri dari batupasir tufaan, batulempung dan konglomerat. Formasi ini berumur Miosen Tengah sampai Miosen Atas.

2. Di atas Formasi Halang, secara tidak selaras, terdapat Breksi Terlipat (Qob) yang terdiri dari breksi gunungapi bersifat andesitik, breksi tufaan, batupasir kasar, batulempung tufaan dan graywacke. Batuan ini berumur Pleistosen Bawah.

3. Endapan Hasil Gunungapi Tua (Qvu) yang menutupi breksi terlipat secara selaras. Endapan Gunungapi Tua terdiri dari breksi lahar, lava andesitik sampai basaltik. Endapan ini berumur Pleistosen Tengah sampai Pleistosen Atas.

Produk termuda stratigrafi ini adalah endapan alluvium (Qa) yang diendapkan di atas formasi-formasi lainnya.

\section{METODE}

Pada penelitian ini dilakukan pemetaan geologi dan geologi teknik untuk menentukan kondisi geologi dan geologi teknik daerah penelitian. Selanjutnya berdasarkan data tersebut dilakukan pengamatan diskontinuitas pada lereng batuan di daerah penelitian menggunakan metode scanline sampling. Data tersebut digunakan untuk menentukan kestabilan lereng batuan menggunakan metode kinematik untuk menentukan tipe keruntuhan batuan (Hoek dan Bray, 1981 dalam Sophian $d k k .$, 2019) dan perhitungan kelas massa batuan. Kedua data tersebut akan digunakan untuk menentukan tingkat kestabilan lereng batuan pada daerah penelitian (Bieniawski, 1989) dengan perhitungan SMR (Romana, 1985).

\section{HASIL DAN PEMBAHASAN}

Berdasarkan hasil pemetaan geologi daerah penelitian, geomorfologi daerah penelitian dibagi menjadi tiga satuan geomorfologi, yaitu Satuan Geomorfologi Perbukitan Berlereng Curam Struktural, Satuan Geomorfologi Perbukitan Berlereng Miring Denudasional, dan Satuan Geomorfologi Perbukitan Rendah Berlereng Sedikit Miring Fluvial (Verstappen dan van Zuidam, 1975). Stratigrafi daerah penelitian dibagi menjadi empat satuan batuan, yaitu dari yang tertua ke yang muda adalah satuan breksi vulkanik sisipan batupasir yang secara selaras diendapkan satuan batulempung. Di atasnya, secara tidak selaras diendapkan satuan breksi tufa. Satuan paling muda pada daerah penelitian adalah endapan alluvial. Struktur geologi daerah penelitian berupa Sesar turun mengiri Sungai 
Cimanuk (Rikard, 1972 dalam Djuri, 1995), dengan orientasi baratdaya - timurlaut serta antiklin Sungai Cimanuk dengan orientasi sumbu relatif baratlaut - tenggara.

\section{Geologi Teknik Daerah Penelitian}

Klasifikasi satuan geologi teknik daerah penelitian untuk tingkat pelapukan mengacu kepada klasifikasi International Society for Rock Mechanic (Barton, 1978 dalam Shang, Hencher dan West, 2015) seperti terlihat pada Tabel 1. Secara garis besar keteknikan batuan lapuk merupakan upaya untuk mengetahui adanya urutan perubahan akibat adanya proses pelapukan fisik dan kimia yang berperan dalam individu atau kombinasinya, beserta sifat - sifat keteknikan pada masing masing derajat pelapukannya.

Berdasarkan klasifikasi tersebut, geologi teknik daerah penelitian dibagi menjadi enam satuan geologi teknik, yaitu satuan Batuan Lapuk Ringan (SW), Batuan Lapuk Sedang (MW), Batuan Lapuk Kuat (HW), Tanah Pasir Kerikil Lapuk Sempurna (CW), dan Tanah Lempung - Pasir Lapuk Sangat Sempurna (XW).

Tabel 1. Klasifikasi derajat pelapukan ISRM (Shang, Hencher dan West, 2015)

\begin{tabular}{|c|c|c|c|c|c|c|c|}
\hline \multirow[b]{3}{*}{ Klasifikasi } & \multirow[b]{3}{*}{ Pemerian } & \multicolumn{5}{|c|}{ Karakteristik } & \multirow[b]{3}{*}{$\begin{array}{c}\text { Suara } \\
\text { Pukulan }\end{array}$} \\
\hline & & \multicolumn{2}{|c|}{ Kenampakan } & \multicolumn{3}{|c|}{ Rekahan } & \\
\hline & & Batuan & $\begin{array}{l}\text { Mineral dan } \\
\text { Batuan }\end{array}$ & Ikatan & Isian & $\begin{array}{l}\text { Ketahanan } \\
\text { Terhadap } \\
\text { Pemisahan }\end{array}$ & \\
\hline FR & $\begin{array}{l}\text { Tidak terlihat tanda-tanda } \\
\text { pelapukan pada mineral batuan: } \\
\text { mungkin sedikit terjadi dari } \\
\text { perubahan warna dari kenampakan } \\
\text { utama pada permukaan }\end{array}$ & $\begin{array}{l}\text { Sangat } \\
\text { segar } \\
\text { dan } \\
\text { keras }\end{array}$ & $\begin{array}{l}\text { Tidak ada } \\
\text { pelapukan dan } \\
\text { alterasi }\end{array}$ & Sangat Kuat & Tidak ada & - & Nyaring \\
\hline $\mathrm{SW}$ & $\begin{array}{l}\text { Perubahan warna menjadi indikasi } \\
\text { pelapukan material batuan dan } \\
\text { permukaan. Semua material } \\
\text { mungkin mengalami perubahan } \\
\text { warna akibat pelapukan atau hal } \\
\text { lain yang terbentuk dari luar dari } \\
\text { kondisi awal yang segar }\end{array}$ & $\begin{array}{l}\text { Segar } \\
\text { dan } \\
\text { keras }\end{array}$ & $\begin{array}{l}\text { Sebagian } \\
\text { sedikit } \\
\text { pelapukan dan } \\
\text { alterasi }\end{array}$ & Kuat & Tidak ada & - & Nyaring \\
\hline$M W$ & $\begin{array}{l}\text { Kurang dari setengah mineral } \\
\text { batuan mengalami dekomposisi } \\
\text { atau disintegritas dengan soil. } \\
\text { Kondisi batu segar atau berubah } \\
\text { warna hadir sebagai kerangka atau } \\
\text { inti batuan }\end{array}$ & $\begin{array}{l}\text { Relatif } \\
\text { keras }\end{array}$ & $\begin{array}{l}\text { Sedikit lapuk } \\
\text { kecuali kuarsa }\end{array}$ & $\begin{array}{l}\text { Sedikit } \\
\text { Terbuka }\end{array}$ & $\begin{array}{l}\text { Limanit } \\
\text { atau } \\
\text { mineral } \\
\text { lempung }\end{array}$ & $\begin{array}{l}\text { Lepas dengan } \\
\text { pukulan kuat } \\
\text { palu geologi }\end{array}$ & Kuat Nyaring \\
\hline $\mathrm{HW}$ & $\begin{array}{l}\text { Lebih dari setengah material } \\
\text { batuan mengalami dekomposisi } \\
\text { dengan soil. Kondisi batu segar } \\
\text { atau berubah warna hadir sebagai } \\
\text { kerangka atau inti batuan }\end{array}$ & $\begin{array}{l}\text { Sedikit } \\
\text { lunak }\end{array}$ & $\begin{array}{l}\text { Sedikit lapuk } \\
\text { kecuali kuarsa } \\
\text { dan agak lunak }\end{array}$ & Terbuka & $\begin{array}{l}\text { Mineral } \\
\text { lempung }\end{array}$ & $\begin{array}{l}\text { Mudah } \\
\text { dipisahkan } \\
\text { dengan } \\
\text { pukulan } \\
\text { sedang palu } \\
\text { geologi } \\
\end{array}$ & Agak Lebam \\
\hline $\mathrm{CW}$ & $\begin{array}{l}\text { Semua material batuan mengalami } \\
\text { dekomposisi atau disintegrasi } \\
\text { dengan soil. Masa batuan asal } \\
\text { tetap utuh }\end{array}$ & Lunak & $\begin{array}{l}\text { Lapuk sedang } \\
\text { dan lunak }\end{array}$ & Terbuka & $\begin{array}{l}\text { Mineral } \\
\text { lempung }\end{array}$ & $\begin{array}{l}\text { Mudah } \\
\text { dipisahkan } \\
\text { dengan } \\
\text { pukulan } \\
\text { ringan palu } \\
\text { geologi } \\
\end{array}$ & Lebam \\
\hline$X W$ & $\begin{array}{l}\text { Semua material batuan berubah } \\
\text { menjadi soil. Masa struktur batuan } \\
\text { dan mineral fabrik telah hancur. } \\
\text { Ada perubahan besar pada } \\
\text { volume, namun jumlah soil yang } \\
\text { tertransportasi tidak signifikan }\end{array}$ & Hancur & $\begin{array}{l}\text { Lapuk kuat dan } \\
\text { perubahan } \\
\text { (dekomposisi) }\end{array}$ & Terbuka & $\begin{array}{l}\text { Mineral } \\
\text { lempung }\end{array}$ & $\begin{array}{l}\text { Sangat } \\
\text { mudah } \\
\text { dilepaskan } \\
\text { dengan } \\
\text { pukulan } \\
\text { ringan pau } \\
\text { geologi }\end{array}$ & Sangat Lebam \\
\hline
\end{tabular}




\section{Analisis Kinematik}

Berdasarkan peta geologi dan geologi teknik yang telah dibuat, lereng yang dijadikan obyek penelitian terletak pada tebing barat Sungai Cimanuk lama di bagian barat spillway Bendungan Jatigede yaitu pada satuan breksi vulkanik sisipan batupasir. Pada lereng tersebut terdapat banyak dikontinuitas yang dikhawatirkan akan menyebabkan terjadinya runtuhan batuan. Pada lereng tersebut terdapat 15 segmen scanline, yaitu SL1 SL15. Panjang tiap segmen scanline $10 \mathrm{~m}$ tercantum pada Tabel 2. Dalam penelitian ini, metode kinematik yang digunakan untuk mengetahui potensi keruntuhan lereng batuan menggunakan teknik stereografis berdasarkan klasifikasi tipe keruntuhan batuan (Hoek dan Bray, 1981 dalam Sophian $d k k ., 2019)$, seperti tercantum pada Gambar 1. Teknik stereografis merupakan metode grafis yang digunakan untuk menunjukan jurus dan kemiringan dari suatu bidang. Pengeplotan secara bersamaan antara jurus dan kemiringan, muka lereng maupun bidang lemah akan segera dapat mengetahui jenis dan arah keruntuhannya.

Tabel 2. Rekapitulasi hasil analisis kinematik seluruh segmen scanline

\begin{tabular}{ccc}
\hline Scanline & Potensi Keruntuhan & Set Diskontinuitas Terlibat \\
\hline SL1 & Baji & JS1 dan JS2 \\
SL2 & Baji & JS1 dan JS2 \\
SL3 & Baji & JS1 dan JS2 \\
SL4 & Baji & JS1 dan JS2 \\
SL5 & Baji & JS1 dan JS2 \\
SL6 & Baji & JS1 dan JS2 \\
SL7 & Baji & JS1 dan JS2 \\
SL8 & Baji & JS1 dan JS2 \\
SL9 & Baji & JS1 dan JS2 \\
SL10 & Baji & JS1 dan JS2 \\
SL11 & Baji & JS1 dan JS2 \\
SL12 & Baji & JS1 dan JS2 \\
SL13 & Baji & JS1 dan JS2 \\
SL14 & Baji & JS1 dan JS2 \\
SL15 & Baji & JS1 dan JS2 \\
\hline
\end{tabular}

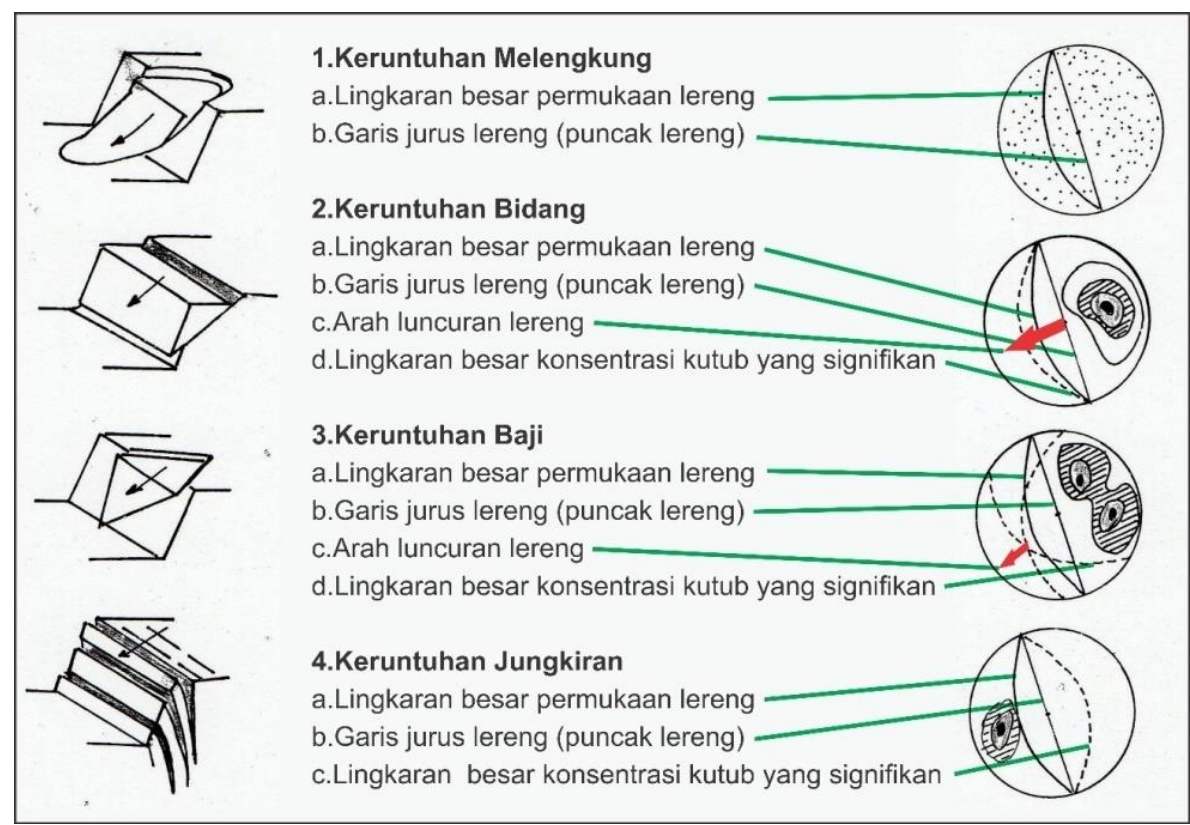

Gambar 1. Tipe keruntuhan batuan (Hoek dan Bray, 1981 dalam Abbas dan Konietzky, 2017) 
Berdasarkan analisis kinematik tipe keruntuhan batuan maka pada seluruh segmen scanline didapat tipe keruntuhan baji dengan bidang diskontinuitas yang berperan dalam potensi keruntuhan tersebut berupa fracture (kekar).

\section{Metode Rock Mass Rating (RMR)}

Klasifikasi geomekanika atau Rock Mass Rating merupakan salah satu pengklasifikasian massa batuan yang bertujuan untuk mengetahui perilaku massa batuan untuk berbagai jenis rekayasa dan jenis perkuatan yang dibutuhkan atas dasar basis data empiris (support requirements based on empirical database).
Klasifikasi ini dikembangkan oleh Bieniawski (1989) dengan pertimbangan bahwa sebuah klasifikasi massa batuan memiliki parameter yang harus diukur dan diamati, yaitu kuat tekan uniaksial material batuan, nilai rock quality designation (RQD), spasi diskontinuitas, kondisi diskontinuitas, serta kondisi keairan yang memiliki bobot yang berpengaruh terhadap nilai klasifikasi masa batuan (Tabel 3).

Berdasarkan klasifikasi RMR 15 segmen scanline daerah penelitian, didapat hasil perhitungan kelas massa batuan Lereng SL1, SL2, SL3, SL4, SL5, SL6 memiliki lereng yang lebih stabil dengan kelas II (good rock) dengan nilai RMR berkisar antara 61-63, sementara segmen lainnya memiliki nilai RMR sebesar 51-58 yang masuk dalam kelas III (fair rock) (Tabel 4).

Tabel 3. Parameter klasifikasi RMR dan nilai pembobotannya (Bieniawski, 1989 dalam Sophian dkk., 2019)

\begin{tabular}{|c|c|c|c|c|c|}
\hline \multirow{2}{*}{\multicolumn{2}{|c|}{ Parameter }} & \multicolumn{4}{|c|}{ Tipe Massa Batuan } \\
\hline & & Tipe 1 & Tipe 2 & Tipe 3 & Tipe 4 \\
\hline \multirow{2}{*}{$\begin{array}{l}\text { Kekuatan Batuan } \\
\text { Utuh(UCS) }\end{array}$} & Nilai (Mpa) & $100-250$ & $25-50$ & $25-50$ & $10-25$ \\
\hline & Peringkat & - & - & - & - \\
\hline \multirow{2}{*}{$\begin{array}{l}\text { Rock Quality } \\
\text { Designation (RQD) }\end{array}$} & Nilai (\%) & - & - & - & - \\
\hline & Peringkat & - & - & - & - \\
\hline \multirow{2}{*}{$\begin{array}{l}\text { Jarak Antar Bidang } \\
\text { Diskontinyu }\end{array}$} & Jarak (m) & - & - & - & - \\
\hline & Peringkat & 20 & 20 & 10 & 10 \\
\hline \multirow[t]{2}{*}{$\begin{array}{l}\text { Kondisi Bidang } \\
\text { Diskontinu }\end{array}$} & $\begin{array}{l}\text { Kekasaran } \\
\text { permukaan } \\
\text { Kemenerusan, } \\
\text { spasi, } \\
\text { dan tingkat } \\
\text { pelapukan }\end{array}$ & $\begin{array}{c}\text { Permukaan kekar } \\
\text { kasar } \\
\text { bukaan }<1 \mathrm{~mm} \text {, } \\
\text { dindingnya } \\
\text { segar, terdapat } \\
\text { oksida besi }\end{array}$ & $\begin{array}{c}\text { Permukaan kekar } \\
\text { kasar } \\
\text { bukaan rapat, } \\
\text { dindingnya } \\
\text { segar }\end{array}$ & $\begin{array}{c}\text { Permukaan kekar } \\
\text { kasar } \\
\text { bukaan }<1 \mathrm{~mm}, \\
\text { dindingnya } \\
\text { segar }\end{array}$ & $\begin{array}{c}\text { Permukaan kekar } \\
\text { kasar } \\
\text { bukaan }<5 \mathrm{~mm}, \\
\text { dindingnya } \\
\text { segar }\end{array}$ \\
\hline & Peringkat & 25 & 30 & 25 & 18 \\
\hline \multirow{2}{*}{ Kondisi Air Tanah } & Aliran (It/m) & Kering & Kering & Kering & Kering \\
\hline & Peringkat & 15 & 15 & 15 & 15 \\
\hline \multirow[t]{2}{*}{$\begin{array}{l}\text { Arah/kemiringan } \\
\text { Bidang Diskontinyu }\end{array}$} & $\begin{array}{l}\text { Arah jurus dan } \\
\text { kemiringan } \\
\text { bidang } \\
\text { diskontinu } \\
\text { terhadap } \\
\text { arah galian }\end{array}$ & $\begin{array}{c}\text { arah galian lereng } \\
\left(\mathrm{N} 5^{\circ} \mathrm{E}\right) \\
\text { dengan kemiringan } \\
\text { bidang diskontinyu } \\
\text { hingga } 70^{\circ}\end{array}$ & $\begin{array}{c}\text { arah galian lereng } \\
\text { dengan kemiringan } \\
\text { bidang diskontinyu } \\
\text { hingga } 85^{\circ}\end{array}$ & $\begin{array}{c}\text { arah galian lereng } \\
\text { dengan kemiringan } \\
\text { bidang diskontinyu } \\
\text { hingga } 86^{\circ}\end{array}$ & $\begin{array}{c}\text { arah galian lereng } \\
\text { dengan kemiringan } \\
\text { bidang diskontinyu } \\
\text { hingga } 76^{\circ}\end{array}$ \\
\hline & Peringkat & -10 & -10 & -10 & -10 \\
\hline \multirow{3}{*}{ RMR } & Peringkat & 95 & 89 & 74 & 55 \\
\hline & Kelas & 1 & 1 & 2 & 3 \\
\hline & Deskripsi & Very Good & Very Good & Good & Fair \\
\hline \multirow{2}{*}{$\begin{array}{l}\text { Parameter } \\
\text { Geomekanika }\end{array}$} & Kohesi (kPa) & $>0.4$ & $>0.4$ & $0.3-0.4$ & $0.2-0.3$ \\
\hline & $\begin{array}{l}\text { Sudut Geser } \\
\text { Dalam }\left({ }^{\circ}\right)\end{array}$ & $>45^{\circ}$ & $>45^{\circ}$ & $35^{\circ}-45^{\circ}$ & $25^{\circ}-35^{\circ}$ \\
\hline
\end{tabular}

Tabel 4. Kelas RMR berdasarkan nilai pembobotanya (Bieniawski, 1989 dalam Sophian dkk., 2019)

\begin{tabular}{cccccc}
\hline Pembobotan & $100-81$ & $80-61$ & $60-41$ & $40-21$ & $>21$ \\
\hline Nomor kelas & I & II & III & IV & V \\
Pemerian & Sangat baik & Baik & Sedang & Jelek & Sangat jelek \\
\hline
\end{tabular}




\section{Metode Slope Mass Rating}

Hasil analisis metode kinematik dan perhitungan klasifikasi massa batuan, digunakan untuk perhitungan kelas massa lereng (slope mass rating). Slope mass rating juga merupakan salah satu sistem klasifikasi massa batuan yang bertujuan untuk mengetahui potensi keruntuhan lereng, tipe keruntuhan lereng dan untuk memilih jenis perkuatan yang sesuai atas dasar basis data empiris dengan persamaan umum yang dipakai:

$$
S M R=R M R_{\text {basic }}+(F 1 \times F 2 \times F 3)+F 4
$$

Berdasarkan perhitungan SMR tersebut maka didapat nilai SMR pada 15 segmen scanline (Tabel 5).

\section{REKOMENDASI DESAIN STABILITAS LERENG}

Untuk memilih jenis perkuatan lereng yang sesuai dalam mencegah terjadinya keruntuhan pada lereng batuan, digunakan sistem SMR. Jenis - jenis perkuatan yang dapat digunakan untuk upaya stabilitas lereng batuan dapat dibagi menjadi sembilan kelas yang berbeda (Romana, 1985 dalam Kundu dkk., 2017).

Berdasarkan Tabel 4, lereng pada SL7, SL8, SL9, SL10, SL11, SL12, SL13, SL14, SL15 yang memiliki kisaran SMR 42 sampai dengan 50 termasuk kategori kelas IIlb. Pada lereng lereng tersebut dapat digunakan perkuatan jenis paritan pada kaki lereng (toe ditch) dan / atau dengan jala kawat (nets), baut batuan (bolting) dan beton semprot (shotcrete) dengan kombinasi jangkar kabel (anchor) dibuat secara sistematis, dengan pembetonan di beberapa bagian kaki lereng.

Lereng pada SL1, SL2, SL3, SL4, SL5, SL6 dengan nilai SMR 52,75 sampai dengan 54,68 termasuk ke dalam kategori kelas IIla (Tabel 6). Pada lereng ini, jenis perkuatan yang dibutuhkan berupa paritan pada kaki lereng (toe ditch), dan / atau penggunaan jala kawat (nets), pada beberapa titik lereng atau secara sistematis menggunakan baut batuan (bolting), dan beton semprot (shotcrete) pada beberapa bagian lereng.

Tabel 6. Nilai SMR pada 15 segmen scanline

\begin{tabular}{cccc}
\hline Scanline & $\begin{array}{c}\text { Total } \\
\text { Nilai } \\
\text { RMR }\end{array}$ & Kelas SMR & $\begin{array}{c}\text { Kelas } \\
\text { Penyangga }\end{array}$ \\
\hline SCL1 & 54,68 & III (Normal) & IIIa \\
SCL2 & 54,68 & III (Normal) & IIIla \\
SCL3 & 54,68 & III (Normal) & IIIa \\
SCL4 & 52,75 & III (Normal) & IIIa \\
SCL5 & 54 & III (Normal) & IIIa \\
SCL6 & 52 & III (Normal) & IIIla \\
SCL7 & 50 & III (Normal) & IIIb \\
SCL8 & 48,75 & III (Normal) & IIIb \\
SCL9 & 42 & III (Normal) & IIIb \\
SCL10 & 49 & III (Normal) & IIIb \\
SCL11 & 42,75 & III (Normal) & IIIb \\
SCL12 & 49 & III (Normal) & IIIb \\
SCL13 & 45,75 & III (Normal) & IIIb \\
SCL14 & 47 & III (Normal) & IIIb \\
SCL15 & 48,75 & III (Normal) & IIIb \\
\hline
\end{tabular}

Tabel 5. Nilai pembobotan kekar (Romana, 1985 dalam Zakaria $d k k ., 2013$ )

\begin{tabular}{|c|c|c|c|c|c|c|}
\hline z & $\begin{array}{c}\text { Kriteria faktor } \\
\text { koreksi }\end{array}$ & $\begin{array}{c}\text { Sangat } \\
\text { menguntungkan }\end{array}$ & Menguntungkan & Sedang & $\begin{array}{c}\text { Tidak } \\
\text { menguntungkan }\end{array}$ & $\begin{array}{c}\text { Sangat tidak } \\
\text { menguntungkan }\end{array}$ \\
\hline$P$ & $|\alpha j-\alpha s|$ & $>30$ & $30-20$ & $20-10$ & $10-5$ & $<5$ \\
\hline $\mathrm{T}$ & $|\alpha j-\alpha s-180|$ & $>30$ & $30-20$ & $20-10$ & $10-5$ & $<5$ \\
\hline $\mathrm{P} / \mathrm{T}$ & $\mathrm{F} 1$ & 0,15 & 0,4 & 0,7 & 0,85 & 1 \\
\hline $\mathrm{P}$ & $|\beta j|$ & $<20$ & $20-30$ & $30-35$ & $35-45$ & $>45$ \\
\hline $\mathrm{P}$ & $\mathrm{F} 2$ & 0,15 & 0,4 & 0,7 & 0,85 & 1 \\
\hline $\mathrm{T}$ & $\mathrm{F} 2$ & 1 & 1 & 1 & 1 & 1 \\
\hline $\mathrm{P}$ & $\beta j-\beta s$ & $>10$ & $10-0$ & 0 & $0-(-10)$ & $<-10$ \\
\hline $\mathrm{T}$ & $\beta j+\beta s$ & $<100$ & $110-120$ & $>120$ & - & - \\
\hline $\mathrm{P} / \mathrm{T}$ & F3 & 0 & -6 & -25 & -50 & -60 \\
\hline
\end{tabular}




\section{KESIMPULAN}

1. Analisis kinematik 15 segmen scanline daerah penelitian, pada umumnya terdapat tipe keruntuhan baji pada seluruh segmen scanline daerah penelitian.

2. Kelas masa batuan pada SL1, SL2, SL3, SL4, SL5, dan SL6 masuk ke dalam kelas II (good rock), sedangkan pada SL7, SL8, SL9, SL10, SL11, SL12, SL13, SL14, dan SL15 masuk dalam kelas III (fair rock).

3. Nilai SMR yang berkisar antara $42-54,68$ terdapat pada seluruh lereng dan diklasifikasikan dalam kelas III (normal) dengan kondisi lereng stabil sebagian (partially stable). Kestabilan lereng batuan daerah penelitian juga dipengaruhi oleh struktur geologi, yaitu sesar turun mengiri Sungai Cimanuk. Di area tersebut terdapat diskontinuitas berupa kekar (fracture) yang berpengaruh terhadap kedudukan bidang gelincir serta kualitas massa batuan yang juga dipengaruhi oleh litologi penyusun berupa breksi vulkanik sisipan batupasir. Berdasarkan kajian awal desain perkuatan batuan dalam usaha menstabilkan lereng, maka lereng pada SL1, SL2, SL3, SL4, SL5, dan SL6 masuk ke dalam kelas IIIa, sedangkan lereng lainya kelas IIIb.

\section{UCAPAN TERIMA KASIH}

Ucapan terima kasih kepada Dirjen Dikti, melalui hibah bersaing, yang telah mendukung kegiatan penelitian ini dengan nomer : 100/K3/KM/2015 tanggal 23 Februari 2015, dan PU Jatigede yang telah menyediakan fasilitas berupa tempat tinggal dan data lapangan.

\section{DAFTAR PUSTAKA}

Abbas, S. M. dan Konietzky, H. (2017) "Rock mass classification systems," in Introduction to Geomechanics. 09/2017 Ed. Freiberg: Technical University Freiberg, hal. 1-48.

Barton, N. R. (1978) "Suggested methods for the quantitative description of discontinuities in rock masses: International Society for Rock Mechanics," International Journal of Rock Mechanics and Mining Science \& Ceomechanics, 15(6), hal. 319-368.
Bemmelen, R. W. (1949) "General geology of Indonesia and adjacent archipelagos," in The Geology of Indonesia. U.S. Government Printing Office, The Hague.

Bieniawski, Z. T. (1989) Engineering rock mass classifications: a complete manual for engineers and geologists in mining, civil, and petroleum engineering. John Wiley \& Sons.

Djuri (1973) "Peta geologi lembar Arjawinangun, Jawa." Bandung: Pusat Penelitian dan Pengembangan Geologi, hal. 1.

Djuri (1995) "Peta geologi Lembar Arjawinangun, Jawa, skala 1:100.000." Bandung: Pusat Penelitian dan Pengembangan Geologi, hal. 1.

Hoek, E. dan Bray, J. (1981) Rock slope engineering. 3rd Ed. Institution of Mining and Metallurgy.

Kundu, J., Sarkar, K., Tripathy, A. dan Singh, T. N. (2017) "Qualitative stability assessment of cut slopes along the National Highway-05 around Jhakri area, Himachal Pradesh, India," Journal of Earth System Science, 126(8), hal. 112. doi: 10.1007/s12040-017-0893-0.

Prasetya, I., Narenda, R., Wiramsya, A., Sophian, I. dan Muslim, D. (2015) "RMR and SMR as slope stability preliminary studies of Rajamandala limestones mine area," in 10th Asian Regional Conference of IAEG. Kyoto: IAEG, hal. 1-5.

Rikard, M. J. (1972) "Fault Classification: Discussion," GSA Bulletin, 83(88), hal. 2545 - 2546. doi: 10.1130/0016-7606(1972).

Romana, M. (1985) “New adjustment ratings for application of Bieniawski classification to slopes," in Proceedings of International Symposium on the Role of Rock Mechanics. Salzburg: International Society for Rock Mechanics, hal. 49-53.

Shang, J., Hencher, S. dan West, J. (2015) "Tensile strength of incipient rock discontinuities," in Schubert, W. dan Kluckner, A. (ed.) Proceedings of the SRM Regional Symposium EUROCK 2015 \& 64th Geomechanics Colloquium. Salzburg: White Rose University Consortium, hal. 1-6.

Sophian, I., Herlinawati, Khairullah, N., Abdurrokhim, Haryanto, I. dan Hendarmawan (2019) "Preliminary geomechanical analysis on limestones in PPSDM Geominerba campus, Padalarang, West Java," Indonesian Mining Journal, 22(1), hal. 2019. doi: 10.30556/imj.Vol22.No1.2019.985. 
Verstappen, H. T. dan van Zuidam, R. A. (1975) ITC textbook of photo-interpretation. 3rd Ed. International Institute for Aerial Survey and Earth Sciences.

Warman, G. I. dan Indrawan, I. G. B. (2015) "Site investigation for construction of emergency spillway at the Jatigede Dam," Journal of Applied Geology, 7(1), hal. 20-29.
Zakaria, Z., Muslim, D., Sophian, I. dan Anisuzzaman, M. (2013) "Correlation between RMR and SMR based on field data: A case study in limestone mining area in Citatah, West Java, Indonesia," International Journal of Chemical, Environmental \& Biological Sciences (IJCEBS), 1(1), hal. 149-152. 